\title{
Coping Behaviors Mediate Associations between Occupational Factors and Compassion Satisfaction among the Intimate Partner Violence and Sexual Assault Workforce
}

\author{
Karin Wachter ${ }^{1}$ (D) $\cdot$ Rachel Voth Schrag ${ }^{2} \cdot$ Leila Wood $^{3}$ \\ Published online: 17 June 2019 \\ (C) Springer Science+Business Media, LLC, part of Springer Nature 2019
}

\begin{abstract}
The intimate partner violence (IPV) and sexual assault (SA) workforce faces significant occupational stressors yet little is known about positive occupational outcomes associated with this work. Therefore, this study analyzed factors associated with compassion satisfaction among the IPV/SA workforce in one southwestern U.S. state $(n=623)$. Drawing from the Resilience Portfolio Model (Grych et al. 2015), researchers examined the possible role of coping behaviors in mediating associations between compassion satisfaction and workplace resources / assets, perceived job security, and resilience. Analyses revealed partial mediation in the models that included workload, values, and resilience as independent variables, suggesting that these factors both influence workers' coping behaviors and have an independent association with compassion satisfaction. Models investigating control, rewards, community, fairness, and perceived job security indicated significant total effects of the independent variables on compassion satisfaction. Overall, IPV/SA workers who engaged more frequently in a range of coping behaviors reported higher levels of compassion satisfaction. The findings point to implications for organizational and employee practice, including building in worktime for key individual coping behaviors, balancing workloads among staff members, and enhancing organizational level coping strategies, such as team supervision and team care planning.
\end{abstract}

Keywords Domestic violence $\cdot$ Sexual violence $\cdot$ Occupational stress $\cdot$ Resilience

\section{Introduction}

A growing body of research is concerned with the occupational stress and secondary trauma experiences of the intimate partner violence (IPV) and sexual assault (SA) workforce

Karin Wachter

Karin.Wachter@asu.edu

Rachel Voth Schrag

rachel.vothschrag@uta.edu

Leila Wood

leilawood@austin.utexas.edu

1 School of Social Work, Watts College of Public Service \& Community Solutions, Arizona State University, University Center, 411 N Central Ave \#800, Phoenix, AZ 85004, USA

2 School of Social Work, The University of Texas at Arlington, $211 \mathrm{~S}$. Cooper, Arlington, TX 76019, USA

3 School of Social Work, The University of Texas at Austin, 1925 San Jacinto Blvd., Stop D3500, Austin, TX 78712-1405, USA
(Babin et al. 2012; Baird and Jenkins 2003; Bemiller and Williams 2011; Dworkin et al. 2016; Kulkarni et al. 2013; Slattery and Goodman 2009; The Texas Council on Family Violence, 2016). Yet gaps in knowledge remain about what fosters and sustains the well-being and tenure of the IPV/SA workforce over time. Research efforts have highlighted stressful work environments, resource constraints, and high employee turnover in this social service sector (Merchant and Whiting 2015; Mor Barak et al. 2001). The IPV/SA workforce is also among the most at-risk professionals for burnout and secondary traumatic stress (STS) (Baird and Jenkins 2003; Busch-Armendariz et al. 2010; Slattery and Goodman 2009; Ullman and Townsend 2007; Wies 2008). Occupational conditions such low pay, lack of organizational support, and a hostile work environment can reduce job satisfaction and increase turnover intention, leading to retention concerns (Wood et al. 2019). Nevertheless, recent studies highlight strong levels of commitment, mission attachment, and capacity to navigate crises, which may serve to keep IPV/SA workers in occupational roles despite challenging conditions (Wood et al. 2017; Bemiller and Williams 2011; Frey et al. 2017). In an 
effort to contribute to the scant evidence-base concerned with the positive outcomes of this critical work, this study examined factors associated with compassion satisfaction and the mediating role of coping behaviors among IPV/SA workers.

\section{Literature Review}

\section{The Well-Being of the IPV/SA Workforce}

Occupational Stress The IPV/SA workforce is at particular risk for negative workplace experiences due to the trauma- and crisis-oriented nature of the work (Wood et al. 2017; Babin et al. 2012; Baird and Jenkins 2003; Dworkin et al. 2016; Kulkarni et al. 2012; Slattery \& Goodman, Ullman and Townsend 2007). Occupational stress can include compassion fatigue, which comprises employee burnout and STS (Stamm 2005). Burnout involves feelings of depersonalization, exhaustion, and difficulties doing one's job effectively, and is often associated with a very high workload or a nonsupportive work environment (Stamm 2005). STS describes the occupational exposure to the trauma of clients and may involve difficulties sleeping, intrusive thoughts, or avoiding reminders of client experiences (Stamm 2005). Major factors linked to STS and burnout include lack of self-care, uncontrolled work stressors, unresolved trauma, and lack of job satisfaction (Radey and Figley 2007). Organizational factors including resource constraints, racism, bias, lack of control, high caseloads, and low quality of supervision are associated with higher levels of STS and burnout; individual factors such as age, time in the field, and insufficient leisure activities are also related (Wood et al. 2019; Dworkin et al. 2016; Kulkarni et al. 2013; Slattery and Goodman 2009; Ullman and Townsend 2007). Many workers in the IPV/SA field of work have themselves experienced violence or trauma (Wood 2016; Kulkarni et al. 2012; Slattery and Goodman 2009). As such, many workers bring experiences of survivorship to the work, which can be protective and predictive of occupational stress (Dworkin et al. 2016; Slattery and Goodman 2009; Frey et al. 2017).

Compassion satisfaction Although occupational stress is a challenge for the IPV/SA workforce, there are also many positive aspects of being engaged in meaningful work. A less researched aspect of professional life is the pleasure workers derive from being able to do their jobs well, conceptualized as compassion satisfaction (Stamm 2010). Compassion satisfaction informs the occupational stress paradigm by emphasizing the benefits that can come from particularly taxing work. Compassion satisfaction has conceptual roots in positive psychology, acknowledges the potential benefit of working with traumatized populations (Kulkarni et al. 2013) and involves personal affect, resources, and self-care (Radey and Figley
2007). The construct of compassion satisfaction shares conceptual overlap with other positive outcomes research among the IPV/SA workforce, such as vicarious posttraumatic growth and resilience (Frey et al. 2017). As an occupational outcome, compassion satisfaction is associated with resilience (Frey et al. 2017), increased job satisfaction (Wood et al. 2017), and mitigating STS-related anxiety (Samios et al. 2013). Compassion satisfaction is also associated with lower burnout and STS among victim advocates (Cummings et al. 2018) and mental health workers (Ray et al. 2013). Compassion satisfaction can co-occur with burnout and secondary traumatic stress (Conrad and Kellar-Guenther 2006). Compassion satisfaction is associated with increased time in the field, higher levels of empathy, positive emotions, greater feelings of control at work, and value alignment (Killian 2008; Kulkarni et al. 2013; Samios et al. 2013; Wagaman et al. 2015). Harr (2013) asserts that supportive administration, supervision, team mentality, and agency environments are integral to increasing compassion satisfaction.

Resilience Along with having a supportive work environment, individual factors shape work outcomes as well. Resilience is a key factor in positive outcomes associated with social service work. Resilience encapsulates a dynamic process of positive adaptation and healthy functioning following significant adversity, stress, and/or traumatic life events (Luthar et al. 2000; Masten 2011). Individual, interpersonal, and community factors, such as self-regulation, secure attachment, and collective efficacy, are associated with healthy functioning and adaptive outcomes (Luthar et al. 2000; Masten 2007 in Grych et al. 2015). Rather than being a fixed personality trait, dynamic circumstances, stressors, risks, and protective factors interact to shape resilience (Collins 2007; Masten 2011). In the workplace, resilience helps workers to respond effectively to the challenge of occupational stress, and is therefore especially pertinent to social service providers (Grant and Kinman 2012; Collins 2008; Howe 2008). Resilience relates to personal and professional growth, and involves self-care, inner strength, values, motivation, self-advocacy, and energy (Fink-Samnick 2009).

Coping Positive coping behaviors relate to positive occupational outcomes. Closely related to resilience, coping refers to people's ongoing efforts to meet external and internal stressors perceived as challenging or exceeding their resources (Lazarus 2013). In their theory of stress and coping, Lazarus and Folkman (1984) posited that the relationship between person and environment determines an individual's ability to cope, and efforts to cope may also involve signaling to potential support providers a need for support. Positive coping may involve cognitive restructuring to manage the symptoms of distress in contrast to directly addressing the stressor (Collins 2008). Although many coping models exist (Grych 
et al. 2015), the research on occupational coping is still nascent. Research suggests positive coping behaviors promote personal wellness, mitigate occupational stress, and increase compassion satisfaction (Cummings et al. 2018; Ray et al. 2013; Stamm 2005). Not all coping strategies are inherently positive (e.g., drinking to excess, avoidance, and under- or over-eating). An earlier study by Um and Harrison (1998) showed an association between coping strategies employed by clinical social workers and job satisfaction. Bober and Regehr (2006) surveyed 259 helping professionals on their use of coping behaviors, and although most participants in their study believed leisure activities and self-care were useful, they were not associated with decreased traumatic stress scores. Qualitative research adds nuance to understanding coping in IPV/SA professional settings. In a study with rape victim advocates, participants felt informal support in the workplace nurtured their well-being and work; however, fear of burdening their peers and a lack of preparedness inhibited access to sufficient support (Houston-Kolnik et al. 2017).

\section{Conceptual Framework}

The Resilience Portfolio Model (RPM) (Grych et al. 2015) can help articulate factors associated with positive outcomes among the IPV/SA workforce. The model builds on research involving resilience, positive psychology, posttraumatic growth, and coping, and highlights what people do in the face of stress that promotes well-being rather than describing qualities that they possess. The model posits that well-being post-violence exposure is the result of "the characteristics of the adversity, the assets and responses available to them, and their behavior or responses" (Grych et al. 2015, p. 3). The model suggests direct associations between (a) exposure to violence, (b) resources/ assets, (c) appraisals and coping behavior, and (d) psychological health, as well as a number of moderating and mediating pathways. Resources refer to external sources of support (i.e. supportive relationships and environmental factors) and assets relate to the person's characteristics that promote healthy functioning (i.e. regulatory, interpersonal and meaning-making strengths) (Grych et al. 2015, p. 4). Together, resources and assets comprise an individual's "portfolio" of strengths and protection factors (p. 4). Appraisals and coping behavior refer to the meanings people make of violence and adverse events, as well as their responses. The RPM model proposes a main effects relationship between resources/ assets and healthy functioning, as well as a buffering effect between resources/assets and well-being in times of stress. Psychological health relates to a broad definition of well-being and positive affect.

We drew from the RPM to guide the current analysis, which employed data collected from the IPV/SA workforce. To our knowledge, this is the first application of the RPM to examine experiences in a professional context among a workforce systematically exposed to trauma and at high risk for occupational stress. We set out to examine associations between RPM constructs of resources/assets, appraisals and coping behavior, and psychological health, which for the purposes of our analysis we conceptualized as workplace resources and workforce assets, occupational coping behaviors, and workforce well-being. As a secondary analysis, we drew variables from a broader dataset as proxy measures for relevant constructs, highlighted in Table 1 and detailed below in the subsequent section. In brief, for workplace resources, we utilized measures of perceived job security and goodness of fit between individuals and their professional environments, and for workforce assets, we employed a resilience measure. For coping behaviors, we used a coping measure modified for the IPV/SA workforce. As our main outcome of interest, we utilized a measure of compassion satisfaction to reflect the construct of workforce well-being. As previously indicated, exposure to violence is a key factor in the RPM, which we conceptualized as secondary traumatic stress in relation to our sample but did not include in the current analysis.

\section{Study Aim}

This study examined associations and interactions between workplace resources, workforce assets, occupational coping behaviors, and workforce well-being. Four research questions guided the analysis. 1) What is the relationship between workplace resources and workforce assets, and compassion satisfaction? 2) What is the relationship between workplace resources and workforce assets, and coping behaviors? 3) What is the relationship between coping behaviors and compassion satisfaction? 4) How do coping behaviors mediate the relationship between workplace resources and workforce assets, and compassion satisfaction? Prior to conducting the analysis, we hypothesized occupational coping behaviors would partially or fully mediate the associations between workplace resources and workforce assets, and compassion satisfaction.

\section{Methods}

This study draws from a cross-sectional survey that examined experiences among the IPV/SA workforce in one U.S. state in the Southwest. The project identified priorities for enhancing occupational wellness, reducing stress, and developing strategies for worker retention. The University of Texas at Austin's Institutional Review Board reviewed and approved the study.

\section{Recruitment}

The study used a nonprobability purposive sampling approach to recruit respondents from diverse professional roles and organizational settings. Two statewide IPV and SA coalitions contributed to the study design and played key roles in promoting 
Table 1 Adaptation and operationalization of the Resilience Portfolio Model

Key constructs in the Resilience Portfolio Model Adaptation and operationalization of key constructs in the current analysis

(Grych et al. 2015)

Resources: Supportive relationships, environmental Workplace resources measured by six domains of job-person fit (Leiter and Maslach 2006, 2011) factors and perceived job security.

Assets: Regulatory strengths, interpersonal strengths, Workforce assets measured by a resilience scale (Connor and Davidson 2003). meaning-making strengths

Appraisals and coping behavior

Occupational coping behaviors measured by a coping behaviors scale adapted for the IPV/SA workforce (Bober et al. 2006; Kulkarni et al. 2013)

Psychological health: Well-being, affect, competencies, symptoms

Workforce well-being measured by a compassion satisfaction scale (Stamm 2010).

awareness of the study, and disseminating recruitment materials among their constituents. Three criteria established study eligibility: a minimum age of 18 years, current employment in the state where the research took place, and a work role that involved at least $50 \%$ of work time focused on IPV/SA-related issues, and/or employment where IPV and/or SA were a central focus of the organizational mission. Recruitment involved sharing promotional and recruitment materials through IPV/SA agency, social media (Twitter and Facebook), and 15 professional listservs to reach eligible participants also working on college campuses, in medical facilities, and other social service agencies. All promotional and recruitment materials and activities reiterated the voluntary nature of participating in the project and included a link to the survey.

\section{Data Collection Procedures}

Respondents provided their informed consent and accessed the survey questions through a web-based platform (Qualtrics). The survey was open for 36 days in early 2017. Participants who completed the survey had the option to enter a drawing to win one of twenty $\$ 50.00$ gift card. The survey was anonymous and did not collect identifying information about the participants or their employers.

\section{Measures}

Demographics Questions asked respondents to report their age, gender, race / ethnicity, sexual orientation, and work setting.

Compassion Satisfaction (Dependent Variable) The Professional Quality of Life scale (ProQOL, Version 5) assessed positive aspects of doing one's job (Stamm 2010). Compassion satisfaction (10 items) captured positive feelings about people's ability to help, and the pleasure one derives from being able to do one's work well. Example items included, I get satisfaction from being able to help people; I feel invigorated after working with those I help; I believe I can make a difference through my work. For each item, respondents were asked to rate how frequently they experienced these things in the past 30 days in the context of their current work situation $(1=$ never, $2=$ rarely, $3=$ sometimes, $4=$ often, $5=$ very often). The scale indicated good internal consistency (Cronbach alpha $=.87$ ). Higher scores represented a greater level of satisfaction and ability of respondents to be effective caregivers in their job.

Coping Behaviors (Mediator) Survey questions assessed participants' coping behaviors using a modified version of The Time Spent in Coping Strategies scale (Bober et al. 2006) adapted by Kulkarni et al. (2013). The modified inventory included 20 items with three subscales (Cronbach's alpha $=$ .87). The leisure subscale asked about frequency of activities such time with family and hobbies (i.e., time spent with family, entertainment, vacation). The self-care subscale asked about self-care activities e (i.e. hobbies, time with family, developing self-care plans, and stress management training). An additional 7 items added to scale by Kulkarni et al. (2013) asked participants to indicate the amount of time they participate in IPV/SA activities that may serve a coping function (i.e. research, political action, advocacy efforts). Participants rated how often they engaged in leisure, self-care, and advocacy activities using a 4-point Likert scale ranging from "not at all" to "frequently," with an additional option to choose "not applicable."

Workplace Resources (Independent Variables) The Areas of Worklife Scale and perceived job security measured workplace resources.

Areas of Worklife Scale (AWS) The 28-item Areas of Worklife Scale (AWS) assessed job-person fit/misfit within specific domains (Leiter and Maslach 2006, 2011). Participants were asked to rate their perceived level of "fit" or congruence with their job across six domains: workload (5 items; Cronbach's alpha $=.82)$, control (4 items; Cronbach's alpha $=.85)$, reward (4 items; Cronbach's alpha $=.90)$, community (5 items; Cronbach's alpha $=.88)$, fairness ( 6 items; 
Cronbach's alpha $=.88$ ), and values (4 items; Cronbach's alpha $=.85$ ). Items were rated on a 5-point Likert scale ranging from "strongly disagree" to "strongly agree." Workload describes the amount of work expected to be completed within a specified period (sample item: I do not have time to do the work that must be done). Control describes opportunities to make choices and decisions (sample item: I have control over how I do my work). Reward describes financial and social recognition for contributions at work (sample item: I receive recognition from others for my work). Community refers to the quality of an organization's social environment (sample item: People trust one another to fulfill their roles). Fairness describes the degree to which the organization has consistent and equitable rules for all employees (sample item: Resources are allocated fairly here). Values reflect what is important to the organization and its employees (sample item: My values and the organization's values are alike). As meanings and relationships between the six subscales (areas) of work life differ, six scores were calculated separately. Subscales had a four-point range from 1.00 (extreme mismatch) to 5.00 (extreme match) with a midpoint at 3.00 .

Perceived Job Security One question assessed perceived job security. The item, I have a sense of security in my job (job security) was created for the purposes of this study. Survey participants were asked to rate how much they disagreed or

Table 2 Participant demographics $(n=623)$

\begin{tabular}{ll}
\hline & \% \\
\hline Gender Categories $(n=615)$ & \\
Female & 92.9 \\
Male & 5.4 \\
Another gender identity & 1.8 \\
Race ( $n=617)$ & \\
Latinx & 31.6 \\
Black or African-American & 8.3 \\
White or Caucasian- Non-Latinx & 52.8 \\
Other & 7.3 \\
Sexual Orientation ( $n=602)$ & \\
Gay, lesbian, bisexual & 10.1 \\
Heterosexual / straight & 85.4 \\
Another sexual orientation & 3.5 \\
Unsure & 1.0 \\
Work setting ( $n=623$ ) & \\
Dual focused agency (IPV / sexual assault) & 61.6 \\
IPV focused agency & 11.7 \\
Sexual assault focused agency (rape crisis center) & 8.7 \\
Other social service non-profit organization & 3.1 \\
Legal setting & 3.7 \\
Other (Medical, University, Other) & 11.2 \\
\hline
\end{tabular}

agreed with the statement $(1=$ strongly disagree, 2 = disagree, $3=$ agree, $4=$ strongly agree).

Workforce Assets (Independent Variable) The 10-item version of the Connor-Davidson Resilience Scale (CD-RISC-10, 2003) assessed workforce assets. Items were rated based on a 5-point Likert scale ranging from "not true at all" (0) to "true nearly all the time" (4). Example items included: I am able to adapt when changes occur, and I believe I can achieve my goals, even if there are obstacles. Participant scores ranged from 0 to 40 , with higher scores reflecting greater resilience $($ alpha $=.91)$.

\section{Data Analysis}

We evaluated the univariate distribution of each variable and conducted a series of Pearson correlations with all variables of interest. Finally, we conducted mediation analyses to assess pathways through which coping impacts compassion satisfaction among the IPV/SA workforce. These analyses used techniques outlined by Hayes (2018), allowing for the coefficient and confidence intervals to be estimated for each pathway through the use of bootstrapping with 10,000 simulations, also allowing for the estimation of the total mediated effect for each model. All mediation models controlled for key individual demographic factors: age, race, and sexual orientation. Finally, the completely indirect effect $(a x b)$ was assessed for each model to provide insight into the effect size (Preacher and Kelley 2011).

\section{Results}

\section{Univariate Results}

Table 2 presents the demographics of study participants. The majority of respondents identified as female, heterosexual, and currently working at a dual focused agency (IPV/SA). The mean age of respondents $(n=$ 603) was 40.29 years old ( $\mathrm{SD}=12.43$, range: $21-73$ ). Participants employed a wide range of occupational coping behaviors (see Table 3 for details). Table 4 includes the mean score for coping behaviors, as well as for all other variables included in the analysis.

\section{Bivariate Correlations}

Bivariate correlations evaluated links between compassion satisfaction, coping behaviors, and key workplace and individual indicators, including workload, control, rewards, community, fairness, values, perceived job security, and resilience. Compassion satisfaction was significantly correlated with 
Table 3 Endorsement of coping behaviors among respondents $(n=516)$

\begin{tabular}{ll}
\hline Coping Behaviors & $\%$ Endorsing "sometimes" or "frequently" \\
\hline Time with Family & $91.5 \%$ \\
Movies/TV & $89.1 \%$ \\
Hobbies & $74.8 \%$ \\
Regular Supervision & $73.0 \%$ \\
Vacation or Time Off & $71.0 \%$ \\
Discussing cases in team meetings & $65.3 \%$ \\
Case discussion with management & $62.5 \%$ \\
Exercise & $59.0 \%$ \\
Educating other organizations & $59.0 \%$ \\
Planning programs & $57.3 \%$ \\
Participating in local system change efforts & $54.2 \%$ \\
Providing or planning prevention programming & $48.2 \%$ \\
Participating in statewide or national advocacy & $44.9 \%$ \\
Developing self-care plans & $44.5 \%$ \\
Participating in political action & $35.0 \%$ \\
Participating in research & $34.5 \%$ \\
Supervision specifically related to trauma & $33.7 \%$ \\
Stress management training- team & $29.7 \%$ \\
Developing team care plans & $28.7 \%$ \\
Stress management training- individual basis & $28.0 \%$ \\
\hline
\end{tabular}

coping behaviors $(r=.24, p<.00)$, as well as each one of the independent variables included in the analysis (see Table 4).

\section{Mediation Analyses}

The results of the mediation analyses indicate that six domains of job-person fit, perceived job security, and resilience partially or completely influenced compassion satisfaction through coping behaviors. See Table 5 for a statistical summary of each mediation model.

Partial Mediation Models Analyses revealed partial mediation in the models that included workload, values, and resilience as the independent variables, suggesting that these factors both
Table 4 Univariate results and bivariate correlations

\begin{tabular}{|c|c|c|c|c|c|c|c|c|c|c|}
\hline & $\begin{array}{l}\text { Mean }(\mathrm{SD}) / \\
\text { range }\end{array}$ & 1. & 2. & 3. & 4. & 5. & 6. & 7. & 8. & 9. \\
\hline $\begin{array}{l}\text { 1. Compassion } \\
\text { Satisfaction }\end{array}$ & $\begin{array}{c}41.48(7.81) \\
10-50\end{array}$ & - & & & & & & & & \\
\hline $\begin{array}{l}\text { 2. Coping } \\
\text { behaviors }\end{array}$ & $\begin{array}{c}51.62(10.87) \\
16-80\end{array}$ & $.24 *$ & - & & & & & & & \\
\hline 3. Workload & $\begin{array}{c}15.79(4.50) \\
5-25\end{array}$ & $.14^{*}$ & $.18^{*}$ & - & & & & & & \\
\hline 4. Control & $\begin{array}{c}15.09(3.46) \\
4-20\end{array}$ & $.16^{*}$ & $.32 *$ & $.25^{*}$ & - & & & & & \\
\hline 5. Rewards & $\begin{array}{c}14.01(4.03) \\
4-20\end{array}$ & $.17^{*}$ & $.32 *$ & $.29 *$ & $.59 *$ & - & & & & \\
\hline 6. Community & $\begin{array}{l}18.44(4.23) \\
5-25\end{array}$ & $.18^{*}$ & $.32 *$ & $.25^{*}$ & $.49 *$ & $.58^{*}$ & - & & & \\
\hline 7. Fairness & $\begin{array}{c}19.35(5.43) \\
6-30\end{array}$ & $.12 *$ & $.35^{*}$ & $.31 *$ & $.64 *$ & $.62^{*}$ & $.52 *$ & - & & \\
\hline 8. Values & $\begin{array}{c}16.03(2.91) \\
5-20\end{array}$ & $.18^{*}$ & $.29 *$ & $.14^{*}$ & $.53^{*}$ & $.52^{*}$ & $.52 *$ & $.60 *$ & - & \\
\hline 9. Job Security & $3.06(.76) 1-4$ & $.14^{*}$ & $.28 *$ & $.15^{*}$ & $.50 *$ & $.43^{*}$ & $.36^{*}$ & $.44 *$ & $.38^{*}$ & - \\
\hline 10. Resilience & $\begin{array}{c}39.73(6.06) \\
10-50\end{array}$ & $.35^{*}$ & $.31 *$ & $.17 *$ & $.28^{*}$ & $.18^{*}$ & $.20^{*}$ & $.22 *$ & $.30 *$ & $.20^{*}$ \\
\hline
\end{tabular}

*all correlations significant at $p<.005$ 
Table 5 Summary of models testing coping behaviors as a mediator of resources/assets and compassion satisfaction

Compassion Satisfaction

$B \quad \mathrm{SE}(\mathrm{B}) \quad 95 \% \mathrm{C}$

Workload

$\mathrm{A} \rightarrow \mathrm{B}$

.43

$\mathrm{B} \rightarrow \mathrm{C}$

.16

C

$\mathrm{C}^{1}$

$\mathrm{a} \times \mathrm{b}$ (indirect effect)

.26

.19

Control

$\mathrm{A} \rightarrow \mathrm{B}$

.07

$\mathrm{B} \rightarrow \mathrm{C}$

C

$\mathrm{C}^{1}$

$\mathrm{a} \times \mathrm{b}$ (indirect effect)

$.22-.64$

$.10-.22$

$.11-.41$

$.05-.34^{\mathrm{a}}$

$.03-.12$

Rewards

$\mathrm{A} \rightarrow \mathrm{B}$

$\mathrm{B} \rightarrow \mathrm{C}$

$\mathrm{C}$

$\mathrm{C}^{1}$

$\mathrm{a} \times \mathrm{b}$ (indirect effect)

1.02

.75-1.29

.16

$.09-.22$

$.15-.56$

$-.01-.40^{\mathrm{b}}$

$.08-.25$

Community

$\mathrm{A} \rightarrow \mathrm{B}$

$\mathrm{B} \rightarrow \mathrm{C}$

$\mathrm{C}^{1}$

$\mathrm{a} \times \mathrm{b}$ (indirect effect)

.20

.16

$.66-1.11$

$.09-.22$

$.11-.46$

$-.03-.33^{\mathrm{b}}$

$.06-.22$

$\mathrm{A} \rightarrow \mathrm{B}$

$\mathrm{B} \rightarrow \mathrm{C}$

$\mathrm{C}$

$\mathrm{C}^{1}$

$\mathrm{a} \times \mathrm{b}$ (indirect effect)

.88

.12

.09

.09

14

.04

$.65-1.08$

$.09-.22$

$.12-.45$

$-.02-.32^{\mathrm{b}}$

$.06-.21$

$\mathrm{A} \rightarrow \mathrm{B}$

$\mathrm{B} \rightarrow \mathrm{C}$

$\mathrm{C}$

$\mathrm{C}^{1}$

$\mathrm{a} \times \mathrm{b}$ (indirect effect)

.11

$.10-.23$

$.03-.28$

$-.09-.17^{\mathrm{b}}$

$.06-.18$

Perceived Job Security

$\mathrm{A} \rightarrow \mathrm{B}$

.71

.08

.03
.06

.07

.04

$\mathrm{B} \rightarrow \mathrm{C}$

$\mathrm{C}$

.15

1.52

$\mathrm{C}^{1}-\frac{.88}{2}$

$.09-.22$

$.61-2.43$

$-.06-1.81^{\mathrm{b}}$

$\mathrm{a} \times \mathrm{b}$ (indirect effect)

.64

$.27-1.07$

Resilience

$\mathrm{A} \rightarrow \mathrm{B}$

.52

$.37-.69$

$.04-.17$

$.37-.58$

$.31-.53^{\mathrm{a}}$

$\mathrm{C}^{1}$

.47

$.01-.10$

a x b (indirect effect)

.05

All models control for age, gender, race, and sexual orientation

$\mathrm{A} \rightarrow \mathrm{B}$ : regression of IV on Mediator (coping behaviors)

$\mathrm{B} \rightarrow \mathrm{C}$ : regression of mediator (coping behaviors) on DV (compassion satisfaction)

C: Total effect of IV on DV

$\mathrm{C}^{1}$ : Direct effect of IV on DV (minus mediation effect of coping)

A $x$ B: indirect effect of IV on DV through coping behaviors

continued:

${ }^{\mathrm{a}}$ : significant direct effect indicating partial mediation

${ }^{\mathrm{b}}$ : insignificant direct effect indicating full mediation 
Fig. 1 The partial mediating role of coping behaviors on the relationship between workload and compassion satisfaction

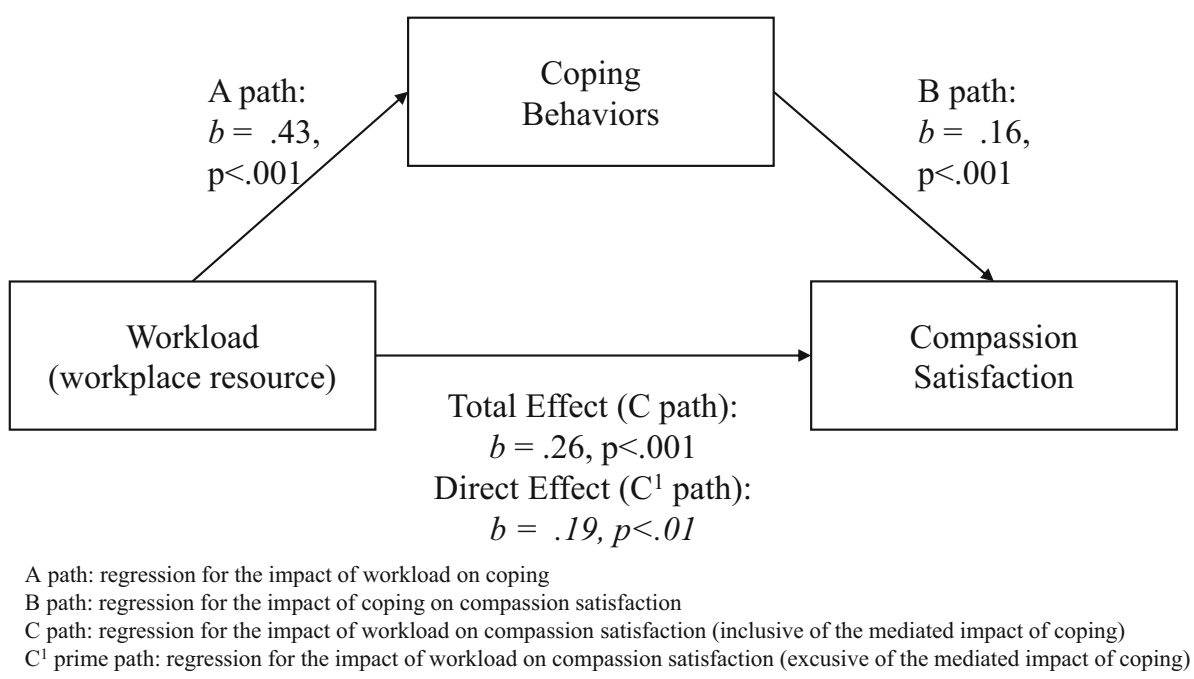

influence workers' coping behaviors and have an independent association with compassion satisfaction. Figure 1 illustrates the workload model, which indicated a significant total effect of workload on compassion satisfaction $(b=.26,95 \% \mathrm{CI}=$ $11-.41)$, as well as a significant direct effect $(b=.19,95 \%$ $\mathrm{CI}=.05-.34)$. The model that assessed the impact of values alignment on compassion satisfaction revealed a significant total effect on compassion satisfaction $(b=.44,95 \%$ $\mathrm{CI}=.20-.68$ ), and a significant direct effect independent of the mediating influence of coping was observed as well ( $b=.2,95 \% \mathrm{CI}=.02-.50)$. The findings of the model exploring the impact of coping behaviors on the link between resilience and compassion satisfaction indicated that resilience had a strong total effect $(b=.47,95 \% \mathrm{CI}=.37-.58)$ and direct effect $(b=.42,95 \% \mathrm{CI}=.31-.53)$ on compassion satisfaction, with comparatively little of the overall effect being transmitted through coping.

Full Mediation Models Models investigating control, rewards, community, fairness, and perceived job security indicated significant total effects of the independent variables on compassion satisfaction. Figure 2 illustrates the control model, which found a significant indirect effect between control and compassion satisfaction through coping behaviors $(b=.16$, $95 \% \mathrm{CI}=.08-.25)$, and an insignificant direct effect $(b=.20$, $95 \% \mathrm{CI}=-.01-.40)$. Similarly, the models for rewards $(b=.14,95 \% \mathrm{CI}=.06-.22)$, community $(b=.13,95 \%$ $\mathrm{CI}=.06-.21)$, fairness $(b=.12,95 \% \mathrm{CI}=.06-.18)$, and perceived job security $(b=.64,95 \% \mathrm{CI}=.27-1.07)$ found significant indirect effects with compassion satisfaction, but insignificant direct effects. Thus, in these models the influence of the independent variable on compassion satisfaction was transmitted through differences in the frequency of workers' coping behaviors.

\section{Discussion}

The aim of this study was to expand knowledge of associations between workplace resources (i.e. workload, values, and
Fig. 2 The full mediating role of coping behaviors on the relationship between control and compassion satisfaction

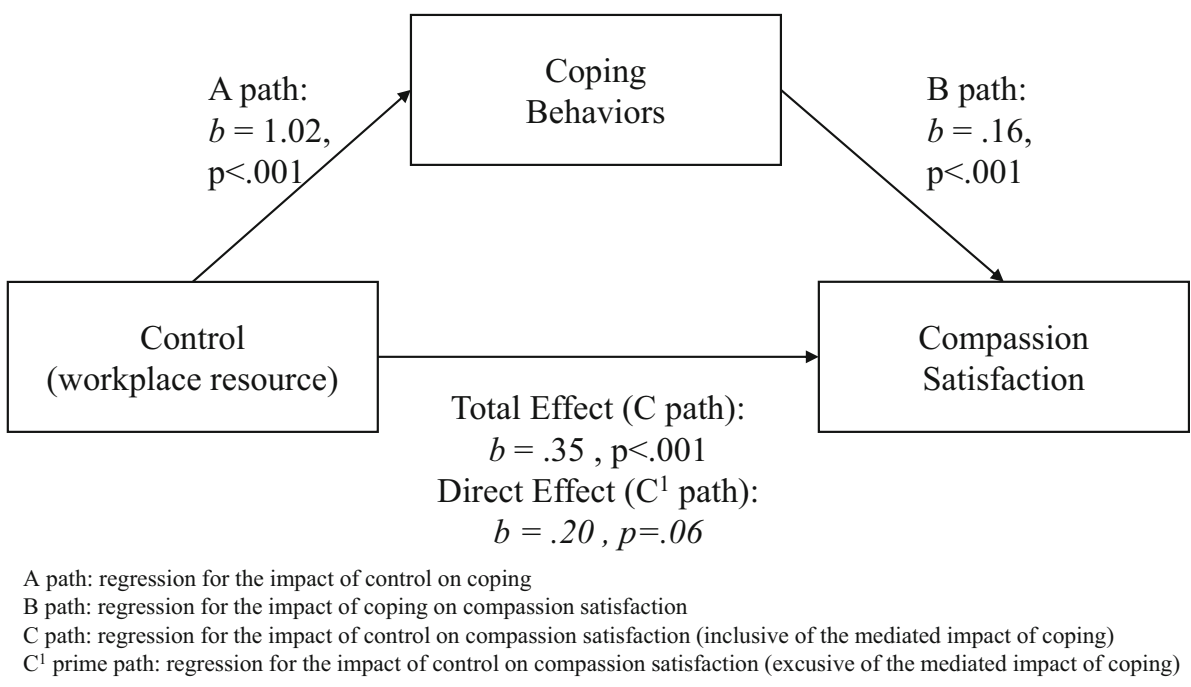


rewards), workforce assets (resilience), occupational coping behaviors, and workforce well-being (compassion satisfaction) among IPV/SA workers. The findings demonstrate that IPV/SA workers who engaged more frequently in a range of coping behaviors reported higher levels of compassion satisfaction. In addition, the findings reveal a nuanced interplay of occupational resources, assets, coping behaviors, and well-being. In support of our hypothesis, the mediation models found significant direct and indirect effects of workload, values, and resilience on compassion satisfaction through coping behaviors, indicating a partially mediating role of coping behaviors in these models. In contrast, our analysis showed statistically insignificant direct effects for compassion satisfaction in the models involving measures of control, rewards, community, fairness, and perceived job security. These models demonstrated effects of occupational factors on compassion satisfaction that were fully mediated by the frequency of coping behaviors. Overall, the findings support the adaptation of the RPM to the IPV/SA occupational context and points to implications for organizational policy and practice.

The analysis reiterates the importance of considering staff well-being among workers at high risk of occupational stress, burnout, and STS. While compassion satisfaction is only one example of positive outcomes associated with stressful work, the construct is significant because it encompasses aspects of the work experience often left out in the daily running of service agencies. Compassion satisfaction speaks to the satisfaction one gets from one's job and from helping other people. It encompasses feelings of invigoration and happiness, a sense of being able to adapt to changes, and the desire to continue because workers feel they can make a difference in people's lives (Stamm 2010, p. 21). As evidenced by previous research, compassion satisfaction is instrumental in staff retention over time, increased empathy, and positive emotions in general (Killian 2008; Kulkarni et al. 2013; Samios et al. 2013; Wagaman et al. 2015). As an important component of worker well-being, compassion satisfaction may thus contribute to improving the functioning of IPV/SA agencies and the quality of services available for violence survivors (Cummings et al. 2018). Adding to the extant literature, our analysis indicates that employers can foster compassion satisfaction by providing workers opportunities to assert control over their work environment, giving meaningful rewards, and building a sense of community and fairness. In addition, addressing imbalanced or extreme workloads, establishing fit between practitioner and agency values, and identifying resilience as an important trait for staff during the hiring process (possibly over certain academic credentials, for example) can all contribute to staff experiencing greater compassion satisfaction. Efforts to cultivate resilience among the workforce are also essential and an important area for intervention research.

The findings highlight a clear association between the frequency of a wide range of coping behaviors and higher reports of compassion satisfaction among IPV/SA workers. Study respondents reported using a range of coping behaviors to manage the stressful nature of their work. Importantly, behaviors occurring outside the workplace and on their staff members' own time were most frequently endorsed; time with family, watching movies and television, engaging in hobbies, and taking vacation and time-off were all frequently endorsed by respondents. In contrast, the least frequently endorsed strategies involved work-place supervision related to trauma, teambased stress management training, developing team care plans, and engaging on an individual basis in stress management training. These findings may reflect the infrequency with which employers offer their workers opportunities to engage in these explicit types of stress reduction activities onsite and during work hours; and point to the degree to which agencies might place the onus for managing stress on workers, and expect workers to devise strategies for coping with stressful work outside of the workplace. In this case, providing work time for these activities, and accommodating staff workloads accordingly, could be an important step by IPV/SA service agencies on the path towards increased worker well-being. However, these findings might alternately reflect how employees perceive and value those types of opportunities. For instance, staff may feel that attending more meetings means less time for work and more stress. Understanding these nuances, using qualitative approaches, would be an important step forward in building the knowledge base.

\section{Implications for Organizational Policy and Practice}

A compelling reason for providing time and space at work for coping-related activities is the important role that coping played in the final mediation models. These models reinforce the importance of encouraging frequency and diversity of behaviors in and out of the workplace that help to alleviate occupational stress among workers. The analyses highlight the critical role coping behaviors play in the well-being of workers in relation to some workforce resources/assets (control, rewards, community, fairness, and perceived job security), and an important but less critical role in relation to others (workload, values, and resilience). Together, the findings point to the importance of organizations in promoting holistic approaches that take into account multiple aspects of worklife to promote well-being, and suggest the importance of fostering regular use of coping behaviors among workers in both personal and professional spheres of life. For organizations, ensuring staff have the time, space, and resources to make full use of coping behaviors is good practice on all levels, as it will pay off in better client services, enhanced worker well-being, and ultimately a more stable workforce, which may help offset many of the costs of taking such steps in the first place.

Indeed, the findings suggest that a singular focus on the promotion of coping behaviors among workers is not enough. 
Employers must address key workplace resources and workforce assets, such as community, fairness, job security, and resilience, hand-in-hand with encouraging and creating opportunities for workers to use coping behaviors. These findings speak to a collaborative approach to fostering well-being among the IPV/SA workforce, in which agencies take responsibility for policies and practices that seek to relieve stress, and workers systematically integrate positive coping strategies into their daily / weekly routines - both in and out of the workplace. Our analysis finds support in a nascent literature on the subject. A systematic review of burnout prevention initiatives indicated longer lasting effects for strategies that were both employee and organization directed (Awa et al. 2010). In addition, efforts to promote resilience among social work students highlighted "interventions that aim to enhance individual coping abilities without recognizing and addressing the structural causes of stress are likely to fail" (Grant and Kinman 2012, p. 617). Findings from a study with domestic violence advocates demonstrated that a workplace environment in which respect for diversity, mutuality, and consensual decision making ("shared power") provided better protection from STS in comparison to traditional hierarchical agency models (Slattery and Goodman 2009).

For agencies and those supervising the IPVS/SA workforce, identifying specific actions that can increase compassion satisfaction could serve as a pathway for reducing burnout, vicarious trauma, and STS (Cummings et al. 2018). While strategies for self-care are considered instrumental to preventing and addressing worker burnout (e.g., Maslach et al. 2012; Newell and MacNeil, 2010), research on the topic is still emerging (Salloum et al. 2015). Conceptualizations of self-care strategies typically include activities such as seeking supervision, working within teams, attending trauma-specific training, balancing caseloads, practicing stress management techniques, developing a plan for work-life balance, and seeking counseling for issues sparked or exacerbated by work (Salloum et al. 2015). These findings suggest that building the agency's awareness of these needs, and implementing workload expectations and agency policies that promote them, could have myriad positive benefits for individual and agencies alike.

Furthermore, as indicated in recent reviews, employee- and organization-led efforts can improve outcomes associated with decreased burnout and improved mental health among workers (Awa et al, 2010; Ahola et al. 2017), although findings are mixed. Examples of interventions tested across an array of high-stress helping professionals and countries include professional skills training, clinical supervision, cognitive behavioral training, and relaxation (Awa et al. 2010). Others have recommended examining the effectiveness of a loving kindness mediation intervention (Fredrickson et al. 2008) and supervision strategies designed to enhance positive emotions, positive reframing, and compassion satisfaction (Samios et al. 2013).
Interventions that seek to foster and provide regular opportunities for peer support among workers may also be worthwhile (Caringi et al. 2017). The evidence also indicates that refresher courses of interventions aimed at supporting worker self-care can help to sustain positive effects over time (Awa et al. 2010).

\section{Implications for Future Research}

Finally, the study points to clear avenues for future research. Questions that emerged from this analysis include whether specific domains of coping behaviors are more or less effective in promoting compassion satisfaction among IPV/SA workers, and the extent to which demographics, type of work, and organizational setting play a role. As such, the analysis points to the need to examine in more depth the range of positive coping behaviors used by the IPV/SA workforce for the purposes of advancing this area of research and organizational policy. Related, although the purpose of this analysis was to focus on positive factors associated with stressful work, an important area of inquiry moving forward would be to understand what negative coping behaviors the IPV/SA workforce may utilize as well. Additionally, use of the RPM in our examination of the well-being of those whose work is traumafocused points to tremendous potential for ongoing research and theory development moving forward.

\section{Limitations}

A number of study limitations are important to note in considering the interpretation and application of the findings. First, the purposive recruitment strategy limits the generalizability of the sample to the study participants. In addition, it is important to take into consideration that the study took place in one U.S. state. The demographics and experiences of participants therefore reflect, to a degree, the workforce of a particular geographic context. Other structural considerations such as levels of funding, inter-agency coordination, and state policy - are also specific to the state in which the study took place. Second, the cross-sectional dataset restricts our ability to draw conclusions as to the direction of associations tested in this analysis, and sparks additional questions about the role compassion satisfaction may play in influencing workers' perspectives and experiences of the workplace. Third, STS is an important factor to consider in relation to the IPV/SA workforce and the theoretical framework employed in this analysis. Although STS was not included in the current analysis, it is in other manuscripts associated with this project (Wood et al. 2019; Voth Schrag et al. in progress). Finally, it is important to acknowledge the challenges of secondary analyses and drawing measures from a broader study that was not originally conceived for the purposes of applying the theoretical model at hand. 


\section{Conclusion}

At multiple levels, the IPV/SA workforce is engaged in meaningful but demanding and stressful work assisting people and their families faced with inter-personal violence and its effects. Compassion satisfaction is a positive outcome of difficult work and an important component of worker well-being. This study highlights a number of important factors that influence the extent to which workers experience compassion satisfaction in their work. It points to the importance of occupational resources, assets, coping behaviors, and individual factors in influencing worker well-being, and suggests that IPV/ SA agencies, supervisors, and employees all have important roles to play in promoting worker well-being.

Acknowledgements We thank the survey participants, as well as the two statewide coalitions and the member organizations for their support of and participation in the study.

Funding The VOICE Survey Project was funded by The Office of the Governor, State of Texas, Criminal Justice Division, Grant Number 3185702 .

\section{References}

Ahola, K., Toppinen-Tanner, S., \& Seppänen, J. (2017). Interventions to alleviate burnout symptoms and to support return to work among employees with burnout: Systematic review and meta-analysis. Burnout research, 4, 1-11.

Awa, W. L., Plaumann, M., \& Walter, U. (2010). Burnout prevention: A review of intervention programs. Patient education and counseling, 78(2), 184-190.

Babin, E. A., Palazzolo, K. E., \& Rivera, K. D. (2012). Communication skills, social support, and burnout among advocates in a domestic violence agency. Journal of Applied Communication Research, 40(2), 147-166. https://doi.org/10.1080/00909882.2012.670257.

Baird, S., \& Jenkins, S. R. (2003). Vicarious traumatization, secondary traumatic stress, and burnout in sexual assault and domestic violence agency staff. Violence and Victims, 18(1), 71-86. https://doi.org/10. 1891/vivi.2003.18.1.71.

Bemiller, M., \& Williams, L. S. (2011). The role of adaptation in advocate burnout: A case of good soldiering. Violence Against Women, 17(1), 89-110. https://doi.org/10.1177/1077801210393923.

Bober, T., \& Regehr, C. (2006). Strategies for reducing secondary or vicarious trauma: Do they work? Brief Treatment and Crisis Intervention, 6(1), 1-9. https://doi.org/10.1093/brief-treatment/mhj001.

Bober, T., Regehr, C., \& Zhou, Y. R. (2006). Development of the coping strategies inventory for trauma counselors. Journal of Loss and Trauma, 11(1), 71-83. https://doi.org/10.1080/15325020500358225.

Busch-Armendariz, N., Kalergis, K., \& Garza, J. (2010). An evaluation of the need for self-care programs in agencies serving adult and child victims of interpersonal violence in Texas. Retrieved May 15, $2019 \mathrm{http}: / / \mathrm{www}$. ncdsv.org/images/UTSW-IDVSA_SelfCareReport_09-09.pdf

Caringi, J. C., Hardiman, E. R., Weldon, P., Fletcher, S., Devlin, M., \& Stanick, C. (2017). Secondary traumatic stress and licensed clinical social workers. Traumatology, 23(2), 186-195.

Collins, S. (2007). Social workers, resilience, positive emotions and optimism. Practice, 19(4), 255-269. https://doi.org/10.1080/ 09503150701728186.
Collins, S. (2008). Statutory social workers: Stress, job satisfaction, coping, social support and individual differences. The British Journal of Social Work, 38(6), 1173-1193. https://doi.org/10.1093/bjsw/ bcm047.

Connor, K. M., \& Davidson, J. R. T. (2003). Development of a new resilience scale: The Connor-Davidson resilience scale (CDRISC). Depression and Anxiety, 18(2), 76-82. https://doi.org/10. 1002/da.10113.

Conrad, D., \& Kellar-Guenther, Y. (2006). Compassion fatigue, burnout, and compassion satisfaction among Colorado child protection workers. Child Abuse \& Neglect, 30(10), 1071-1080. https://doi. org/10.1016/j.chiabu.2006.03.009.

Cummings, C., Singer, J., Hisaka, R., \& Benuto, L. T. (2018). Compassion satisfaction to combat work-related burnout, vicarious trauma, and secondary traumatic stress. Journal of Interpersonal Violence. https://doi.org/10.1177/0886260518799502.

Dworkin, E. R., Sorell, N. R., \& Allen, N. E. (2016). Individual-and setting-level correlates of secondary traumatic stress in rape crisis center staff. Journal of Interpersonal Violence, 31(4), 743-752. https://doi.org/10.1177/0886260514556111.

Fink-Samnick, E. (2009). The professional resilience paradigm: Defining the next dimension of professional self-care. Professional Case Management, 14(6), 330-332. https://doi.org/10.1097/NCM. 0b013e3181c3d483.

Fredrickson, B. L., Cohn, M. A., Coffey, K. A., Pek, J., \& Finkel, S. M. (2008). Open hearts build lives: positive emotions, induced through loving-kindness meditation, build consequential personal resources. Journal of personality and social psychology, 95(5), 1045.

Frey, L. L., Beesley, D., Abbott, D., \& Kendrick, E. (2017). Vicarious resilience in sexual assault and domestic violence advocates. Psychological Trauma: Theory, Research, Practice, and Policy, 9(1), 44-51. https://doi.org/10.1037/tra0000159.

Grant, L., \& Kinman, G. (2012). Enhancing wellbeing in social work students: Building resilience in the next generation. Social Work Education, 31(5), 605-621. https://doi.org/10.1080/02615479. 2011.590931.

Grych, J., Hamby, S., \& Banyard, V. (2015). The resilience portfolio model: Understanding healthy adaptation in victims of violence. Psychology of Violence, 5(4), 343-354 http://dx.doi.org.ezproxy1. lib.asu.edu/10.1037/a0039671.

Harr, C. (2013). Promoting workplace health by diminishing the negative impact of compassion fatigue and increasing compassion satisfaction. Social Work \& Christianity, 40(1), 71-88.

Hayes, J. (2018). The theory and practice of change management. London: Palgrave.

Houston-Kolnik, J. D., Odahl-Ruan, C. A., \& Greeson, M. R. (2017). Who helps the helpers? Social support for rape crisis advocates. Journal of Interpersonal Violence. https://doi.org/10.1177/ 0886260517726970.

Howe, D. (2008). The emotionally intelligent social worker. New York: Macmillan International Higher Education.

Killian, K. D. (2008). Helping till it hurts? A multimethod study of compassion fatigue, burnout, and self-care in clinicians working with trauma survivors. Traumatology, 14(2), 32-44. https://doi.org/10. 1177/1534765608319083.

Kulkarni, S. J., Bell, H., \& Rhodes, D. M. (2012). Back to basics: Essential qualities of services for survivors of intimate partner violence. Violence Against Women, 18(1), 85-101. https://doi.org/10. 1177/1077801212437137.

Kulkarni, S., Bell, H., Hartman, J. L., \& Herman-Smith, R. L. (2013). Exploring individual and organizational factors contributing to compassion satisfaction, secondary traumatic stress, and burnout in domestic violence service providers. Journal of the Society for Social Work and Research, 4(2), 114-130. https://doi.org/10.5243/jsswr.2013.8. 
Lazarus, R. S. (2013). Fifty years of the research and theory of R.s. Lazarus: An analysis of historical and perennial issues. Mahwah: Psychology Press.

Lazarus, R. S., \& Folkman, S. (1984). Stress, appraisal, and coping. New York: Springer Publishing Company, Inc.

Leiter, M. P., \& Maslach, C. (2006). Areas of worklife survey manual. Wolfville: Center for Organizational Research and Development.

Luthar, S. S., Cicchetti, D., \& Becker, B. (2000). The construct of resilience: A critical evaluation and guidelines for future work. Child Development, 71(3), 543-562. https://doi.org/10.1111/1467-8624.00164.

Maslach, C., Leiter, M. P., \& Jackson, S. E. (2012). Making a significant difference with burnout interventions: Researcher and practitioner collaboration. Journal of Organizational Behavior, 33(2), 296-300. https://doi.org/10.1002/job.784.

Masten, A. S. (2007). Resilience in developing systems: Progress and promise as the fourth wave rises. Development and Psychopathology, 19(3), 921-930. https://doi.org/10.1017/ S0954579407000442.

Masten, A. S. (2011). Resilience in children threatened by extreme adversity: Frameworks for research, practice, and translational synergy. Development and Psychopathology, 23(2), 493-506. https://doi. org/10.1017/S0954579411000198.

Merchant, L. V., \& Whiting, J. B. (2015). Challenges and retention of domestic violence shelter advocates: A grounded theory. Journal of Family Violence, 30(4), 467-478. https://doi.org/10.1007/s10896015-9685-y.

Mor Barak, M. E., Nissly, J. A., \& Levin, A. (2001). Antecedents to retention and turnover among child welfare, social work, and other human service employees: What can we learn from past research? A review and metanalysis. Social Service Review, 75(4), 625-661. https://doi.org/10.1086/323166.

Newell, J. M., \& MacNeil, G. A. (2010). Professional burnout, vicarious trauma, secondary traumatic stress, and compassion fatigue. Best Practices in Mental Health, 6(2), 57-68.

Preacher, K., \& Kelley, K. (2011). Effect size measures for mediation models: Quantitative strategies for communicating indirect effects. Psychological Methods, 16(2), 93-115. https://doi.org/10.1037/ a0022658.

Radey, M., \& Figley, C. R. (2007). The social psychology of compassion. Clinical Social Work Journal, 35(3), 207-214. https://doi.org/10. 1007/s10615-007-0087-3.

Ray, S. L., Wong, C., White, D., \& Heaslip, K. (2013). Compassion satisfaction, compassion fatigue, work life conditions, and burnout among frontline mental health care professionals. Traumatology, 19(4), 255-267. https://doi.org/10. $1177 / 1534765612471144$.

Salloum, A., Kondrat, D. C., Johnco, C., \& Olson, K. R. (2015). The role of self-care on compassion satisfaction, burnout and secondary trauma among child welfare workers. Children and Youth Services Review, 49, 54-61.
Samios, C., Abel, L. M., \& Rodzik, A. K. (2013). The protective role of compassion satisfaction for therapists who work with sexual violence survivors: An application of the broaden-andbuild theory of positive emotions. Anxiety, Stress, \& Coping, 26(6), 610-623. https://doi.org/10.1080/10615806.2013. 784278 .

Slattery, S. M., \& Goodman, L. A. (2009). Secondary traumatic stress among domestic violence advocates: Workplace risk and protective factors. Violence Against Women, 15(11), 1358-1379. https://doi. org/10.1177/1077801209347469.

Stamm, B. H. (2005). The ProQOL manual: The professional quality of life scale: Compassion satisfaction, burnout and compassion fatigue/ secondary trauma scales. Retrieved January 15, 2006. http://www. compassionfatigue.org/pages/ProQOLManualOct05.pdf.

Stamm, B. H. (2010). The concise ProQOL manual. Pocatello, ID: ProQOL.org.

Ullman, S. E., \& Townsend, S. M. (2007). Barriers to working with sexual assault survivors: A qualitative study of rape crisis center workers. Violence Against Women, 13(4), 412-443. https://doi.org/ 10.1177/1077801207299191

Um, M. Y., \& Harrison, D. F. (1998). Role stressors, burnout, mediators, and job satisfaction: A stress-strain-outcome model and an empirical test. Social Work Research, 22(2), 100-115

Voth Schrag, R., Wood, L. \& Wachter, K. (in progress). Burnout and secondary traumatic stress among intimate partner violence \& sexual assault service providers: Individual, job level, and organizational influences.

Wagaman, M. A., Geiger, J. M., Shockley, C., \& Segal, E. A. (2015). The role of empathy in burnout, compassion satisfaction, and secondary traumatic stress among social workers. Social Work, 60(3), 201209. https://doi.org/10.1093/sw/swv014.

Wies, J. (2008). Professionalizing human services: A case of domestic violence shelter advocates. Human Organization, 67(2), 221-233. https://doi.org/10.17730/humo.67.2.143m2v5422171113.

Wood, L. (2016). "I look across from me and I see me": Survivors as advocates in intimate partner violence agencies. Violence Against Women, 23(3), 309-321.

Wood, L., Wachter, K., Wang, A., Kammer-Kerwick, M., \& BuschArmendariz, N. (2017). VOICE: Victim services occupation, information, and compensation experiences survey. Austin: Institute on Domestic Violence \& Sexual Assault.

Wood, L., Wachter, K., Rhodes, D. \& Wang, A. (2019). Turnover intention and job satisfaction among intimate partner violence and sexual assault professionals. Violence and Victims. (in press).

Publisher's Note Springer Nature remains neutral with regard to jurisdictional claims in published maps and institutional affiliations. 